\title{
Relaxation Dynamics of Thin Matrimid 5218 Films in Organic Solvents
}

\author{
Kristianne Tempelman, ${ }^{\dagger}$ Jeffery A. Wood, ${ }^{\ddagger}$ Friedrich Kremer, ${ }^{\S}$ and Nieck E. Benes ${ }^{*}{ }^{\dagger}$ (i) \\ ${ }^{\dagger}$ Films in Fluids and ${ }^{\ddagger}$ Soft Matter, Fluidics and Interfaces, Faculty of Science and Technology, MESA ${ }^{+}$Institute for Nanotechnology, \\ University of Twente, P.O. Box 217, 7500 AE Enschede, The Netherlands \\ ${ }^{\S}$ Faculty of Physics and Geosciences, Institute for Experimental Physics I, University of Leipzig, Linnéstr. 5, 04103 Leipzig, Germany
}

Supporting Information

\begin{abstract}
Polyimides are interesting polymer materials for organic solvent nanofiltration (OSN) applications because of their high excess free volume and high chemical and temperature resistance. However, an open challenge that remains for glassy polymer materials (i.e., polyimides) is their tendency to swell in organic solvents which can lead to a loss of performance. An understanding on how swelling influences the polymer properties and performance is then of crucial importance for assessing polyimide suitability in OSN applications. Here, the combination of in situ spectroscopic ellipsometry (iSE), broadband dielectric spectroscopy (BDS), and diffuse reflectance Fourier transform infrared spectroscopy (DRIFT-FTIR) is applied to study

\begin{tabular}{|c|c|c|c|}
\hline & $\begin{array}{l}\text { Spectroscopic } \\
\text { ellipsometry }\end{array}$ & $\begin{array}{l}\text { Broadband } \\
\text { dielectric } \\
\text { spectroscopy }\end{array}$ & $\begin{array}{l}\text { Infrared } \\
\text { spectroscopy }\end{array}$ \\
\hline Dry & $\mathrm{h}_{\mathrm{dry}} \mathrm{t}^{\square}$ & $\underbrace{\beta, \& \beta_{2}}_{\text {Frequency }(\mathrm{Hz})}$ & \\
\hline n-Hexane & $\begin{array}{l}4 \% \text { swelling } \\
\mathrm{h}_{\text {sw }} \text { ? }\end{array}$ & $\overbrace{\text { Frequency }(\mathrm{Hz})}^{\beta_{1}^{\beta_{1}}}$ & \\
\hline Toluene & $\begin{array}{l}28 \% \text { swelling } \\
h_{\text {sw }}\end{array}$ & Frequency $(\mathrm{Hz})$ & $\pi-\pi$ Interaction \\
\hline
\end{tabular}
the molecular interaction of two organic penetrants, toluene and $n$-hexane, with Matrimid 5218 in detail. iSE shows that slightly cross-linked Matrimid 5218 swells approximately seven times more in toluene (swelling degree $\approx 28 \%$ ) compared to in $n$ hexane (swelling degree $\approx 4 \%$ ). Combined BDS and DRIFT-FTIR results indicate that toluene interacts with the benzene ring present in the diamine via $\pi-\pi$ interactions, while $n$-hexane likely fills up the excess free volume and interacts via local van der Waals interactions. This work highlights the insights into the exact nature of the molecular interactions between the penetrant and polymer that can be gained from a combination of BDS and other techniques and how these insights can be used to estimate or understand solvent-induced swelling of polymers used in OSN applications.
\end{abstract}

\section{INTRODUCTION}

High-performance materials such as polyimides are known for their rigid structure, high temperature resistance, and high chemical resistance. Polyimides are for this reason interesting candidates when requiring a high chemical and temperature resistance in applications such as coatings or membranes. ${ }^{1}$ Because of their rigid structure and their tendency to crystallize, many polyimides are nearly insoluble after the imidization treatment. However by incorporating a copolymer structure or steric hindrance by introducing a bulky molecular group, the linearization of the rigid backbone is disrupted and the solubility of the polyimide can be increased which has advantages for processing but also a cost in terms of susceptibility to plasticization. ${ }^{2,3}$ An example of such a nonhomogenous polyimide is Matrimid 5218, from here onward referred to as matrimid. In the field of membrane technology, plasticization is a common problem that causes a lower selectivity of the membrane and therefore the origin of plasticization in polyimides such as matrimid is a wellresearched topic. ${ }^{4-9}$ Because polyimides are considered to have a high potential as gas separation membranes, most of these studies to date have focused on $\mathrm{CO}_{2}$-induced plasticization. ${ }^{4,7,10-13}$ However, because of their high chemical resistance, polyimides are also considered either as a support material or as a selective layer in organic solvent nanofiltration (OSN) applications. ${ }^{14}$ This stresses the importance in studying the plasticization and swelling in polyimides such as matrimid that is induced by organic solvents.

Typically in plasticization studies, ${ }^{15-19}$ the penetrant mass uptake, swelling, or performance of the polyimide are studied as a function of penetrant exposure. Generally, these techniques measure the consequences of the penetrantpolymer interactions but provide no direct insight into the underlying physical phenomena and the specific changes in the dynamics of the penetrant and the polymer. By studying the penetrant-induced relaxation dynamics, information on the site-specific interactions of the penetrant with the molecular groups inside the polymer can potentially be provided. For example, Neubauer et al. ${ }^{20}$ studied in situ the influence of swelling on the molecular dynamics of poly(2-vinyl-pyridine) with broadband dielectric spectroscopy (BDS) utilizing nanostructured electrodes. These molecular insights will allow for selecting new materials and tailoring the chemistries to specific applications. To the best of our knowledge, no research on the penetrant-induced relaxation dynamics for polyimides has been presented to date.

The temperature-dependent relaxation dynamics of polyimides and influence of its two monomers, dianhydride and

Received: January 23, 2019

Revised: $\quad$ March 31, 2019

Published: April 1, 2019 
diamine, have already been studied in the literature. ${ }^{2,3,21-24}$ Typically, for temperatures at room temperature or higher, a $\beta$ relaxation and $\alpha$-relaxation have been observed. $\mathrm{Li}$ et al. $(1999)^{3,25}$ observed for the first time three relaxations above room temperature for a polyimide. They appointed the lower temperature relaxations as $\beta_{1}$ and $\beta_{2}$, and the third process was the $\alpha$-relaxation corresponding with the glass transition. The $\beta_{1}$-relaxation was attributed to the local motion of the diamine constituents, while the $\beta_{2}$-relaxation is considered to be caused by local motion of the dianhydride constituents. They showed by using the Starkweather theory that the $\beta_{2}$-relaxation can transform from a noncooperative process to a cooperative process upon increasing the size and anisotropic shape of the substituted groups on the dianhydride. The two $\beta$-relaxations were also experimentally confirmed later by $\mathrm{Qu}$ et al. ${ }^{2}$ The observed cooperative characteristics of the $\beta$-relaxation have also been observed for other polyimides. ${ }^{21,22,24,26}$

In the case of matrimid, the dynamic polymer chain relaxations of matrimid have been studied by Comer et al. ${ }^{27}$ and Konnertz et al. ${ }^{28}$ as a function of temperature. Both studies utilized BDS, and the $\beta$-relaxation was characterized to be local in nature but cooperative in origin because of the rigid backbone of the matrimid structure. Konnertz et al. proposed that the cooperativity of the $\beta$-relaxation was the result of the $\pi-\pi$ stacking of the phenyl rings. In their work, a temperature history-dependent relaxation behavior of matrimid was observed. Currently, the temperature dependence of the dynamic polymer chain relaxations of matrimid is reasonably understood. However, it is unknown to what extent the introduction of a penetrant will influence the dynamic polymer chain relaxations in which interactions between the penetrant and polymer dominate the swelling behavior and how this couples to the temperature-dependent behavior.

In this work, the interaction of toluene and $n$-hexane with matrimid was studied using a combination of techniques to provide a deeper insight into how common organic solvents influence the relaxation dynamics of matrimid. In situ spectroscopic ellipsometry (iSE) was used to study the swelling upon exposure to the two different penetrants. BDS was applied in situ to probe the dynamic polymer chain relaxations on matrimid while being exposed to the penetrants. In situ diffuse reflectance Fourier transform infrared spectroscopy (DRIFT-FTIR) was used to obtain a molecular interpretation of the different chain relaxations observed upon penetrant exposure. The combination of the three in situ characterization techniques allowed for an interpretation of the exact nature of the molecular interaction between the penetrant, toluene and $n$-hexane, and the polymer, matrimid. The obtained insights can be used to estimate or to understand solvent-induced swelling of polymers used in OSN applications.

\section{EXPERIMENTAL SECTION}

Materials. Matrimid 5218 US (Huntsman) (Figure 1), Cyclopentanone (ReagentPlus, $\geq 99 \%$, Sigma-Aldrich), toluene (EMPLURA, >99\%, Merck), $n$-hexane (EMPLURA, >95\%, Merck), toluene anhydrous (99.8\%, Sigma-Aldrich), and $n$ hexane anhydrous (95\%, Sigma-Aldrich) for the BDS experiments were used as received.

Silicon wafers (100, front side polished, CZ test grade, Silchem) were used as a substrate for the spin-coated layer. The wafers were stored under clean-room conditions until

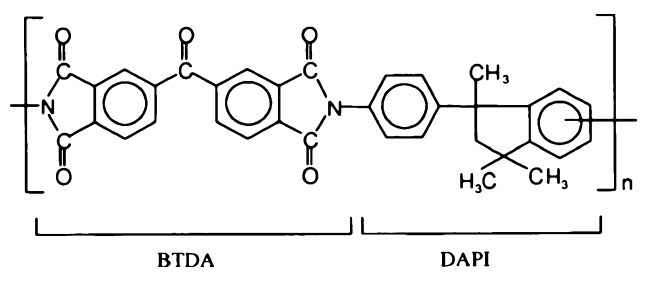

Figure 1. Molecular structure of Matrimid 5218.

being cut. Prior to use, the wafers were cleaned with acetone (Chromasolv plus, for HPLC 99.9\%, Sigma-Aldrich).

Sample Preparation. Cyclopentanone was used as a solvent to prepare 5 and 20 wt \% solutions of matrimid. The solutions were spin-coated (Laurell WS-400B-6NPP-Lite spincoater) on a silicon wafer with a native oxide. For the preparation of the spectroscopic ellipsometry and dielectric samples, a two-step spin-coating program was used. During the first step, a $0.1 \mathrm{~mL} 5 \mathrm{wt} \%$ solution was deposited on the wafer for $10 \mathrm{~s}$ at $500 \mathrm{rpm}$. The second step involved an acceleration of $1710 \mathrm{rpm} \mathrm{s}^{-1}$ to $3000 \mathrm{rpm}$ followed by a constant rotation spinning step of $1 \mathrm{~min}$. The samples for BDS were prepared inside a dust-free room (ISO Class 6) to prevent contamination of the polymer film. For infrared spectroscopy, a spin-coating program of $5 \mathrm{~min}$ at $3000 \mathrm{rpm}$ with an acceleration of $1710 \mathrm{rpm} \mathrm{s}^{-1}$ was used. Solutions (20 wt \%) were deposited prior to spin-coating because of the high solution viscosity.

After spin-coating, the samples have been annealed in a lowtemperature furnace (Carbolite HTMA 5/28) under a nitrogen atmosphere at a temperature of $250{ }^{\circ} \mathrm{C}$ for $1 \mathrm{~h}$, followed by a relaxation step at $350{ }^{\circ} \mathrm{C}$ for $6 \mathrm{~h}$ using a ramp rate of $5{ }^{\circ} \mathrm{C} \mathrm{min}^{-1}$. To enable a controlled cooldown of the samples, the samples were cooled down to $25^{\circ} \mathrm{C}$ with a rate of $0.1{ }^{\circ} \mathrm{C} \mathrm{min}^{-1}$.

In Situ Spectroscopic Ellipsometry. Temperaturedependent and penetrant-dependent thickness and refractive index measurements of the spin-coated matrimid films were performed with spectroscopic ellipsometry. The data were modeled in the CompleteEase software package (J.A. Woollam Co.) in the wavelength range of 400-1000 $\mathrm{nm}$. The substrate was modeled using the built-in temperature-dependent optical properties of silicon, on top of which a $2 \mathrm{~nm}$ native oxide layer was modeled. The matrimid films were modeled using an anisotropic Cauchy dispersion [fit parameters: $\Delta z A$ (anisotropy) to describe the difference between the ordinary and extraordinary Cauchy dispersion, $A, B, C, k$ (of the ordinary Cauchy dispersion) and thickness]. In case of penetrantinduced swelling, an ambient with the optical constants of the penetrant was added to the model. Additional modeling details are provided in the Supporting Information.

Temperature-dependent measurements were performed with a M2000XI spectroscopic ellipsometer (J.A. Woollam Co.) equipped with a Linkam heating stage with quartz windows at an incident angle of $70^{\circ}$. The temperature measurements were performed under ultra-pure nitrogen at a flow rate of $100 \mathrm{~mL} \mathrm{~min}{ }^{-1}$. Temperature correction for the actual temperature of the sample was applied according to the procedure described previous by Kappert et al. ${ }^{29}$ The optical retardance of the windows of the measurement cell was included using calibrated delta off-sets. The freshly spin-coated matrimid films were heated to $250{ }^{\circ} \mathrm{C}$ at a ramp of $5{ }^{\circ} \mathrm{C} \mathrm{min}{ }^{-1}$ and held at $250{ }^{\circ} \mathrm{C}$ for $1 \mathrm{~h}$, followed by another temperature 
ramp of $5{ }^{\circ} \mathrm{C} \mathrm{min}^{-1}$ to $350{ }^{\circ} \mathrm{C}$ at which the sample was held for another $6 \mathrm{~h}$. Finally, the sample was cooled down to $25^{\circ} \mathrm{C}$ at a rate of $0.1{ }^{\circ} \mathrm{C} \mathrm{min}^{-1}$.

Penetrant-induced swelling measurements were performed with an Alpha-SE ellipsometer (J.A. Woollam Co.) and a 500 $\mu \mathrm{L}$ liquid cell at a $70^{\circ}$ angle of incidence. Measurements were performed in liquid $n$-hexane and toluene ${ }^{a}$ at room temperature for approximately $24 \mathrm{~h}$. The liquid cell was filled with the penetrant using a $20 \mathrm{~mL}$ glass syringe. In situ data were recorded once every $\sim 15$ s. The optical retardance of the windows of the measurement cell was included using calibrated delta off-sets (see the Supporting Information).

For each penetrant-induced swelling measurement, the swelling degree (SD) (eq 1) and the normalized refractive index (eq 2) were determined.

$$
\mathrm{SD}=\left(\frac{d_{\text {swollen }}}{d_{\text {dry }}}-1\right) \cdot 100 \%
$$

where SD is the swelling degree and $d_{\text {dry }}$ and $d_{\text {swollen }}$ are the dry and swollen thickness of the film, respectively.

$$
n_{\text {norm }}=\frac{n_{\text {swollen }}-n_{\text {solvent }}}{n_{\text {dry }}-n_{\text {solvent }}}
$$

where $n_{\text {norm }}$ is the normalized refractive index, $n_{\text {dry }}$ is the refractive index of the nonswollen polymer film, $n_{\text {swollen }}$ is the refractive index of the swollen polymer film in a solvent, and $n_{\text {solvent }}$ is the refractive index of the pure solvent.

In Situ Broadband Dielectric Spectroscopy. BDS experiments were performed using a high-resolution Novocontrol Alpha-A analyzer with a ZG4 test interface (Novocontrol Technologies). A homemade sample cell from Leipzig University was used and could be immersed in the liquid penetrants. For the measurements, a parallel plate configuration was used where the bottom electrode was an $8 \times 8$ $\mathrm{mm}^{2}$ silicon wafer (30 nm oxide on top) with a $200 \mathrm{~nm}$ sputtered aluminum layer on the backside and the spin-coated matrimid film on the top side. The $1 \times 1 \mathrm{~mm}^{2}$ top counter electrode was also a $30 \mathrm{~nm} \mathrm{SiO}_{2}$ on a silicon wafer with a 200 $\mathrm{nm}$ sputtered aluminum layer on the backside (see Figure 2).

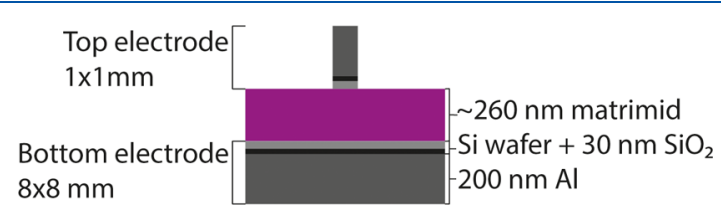

Figure 2. Schematic representation of the parallel plate electrode configuration used for the BDS measurements.

For each sample, the complex dielectric function was measured in a frequency range of $8 \times 10^{-2}$ to $10^{6} \mathrm{~Hz}$ at room temperature, and the alternating current voltage was set at $1.0 \mathrm{~V}$. Prior to each measurement, the sample was purged with dry nitrogen for $1 \mathrm{~h}$. For the penetrant-induced swelling measurements, the BDS sample cell was completely immersed into the liquid penetrant, and continuous frequency sweeps over a range of $24 \mathrm{~h}$ were performed. To dry the sample, a continuous dried nitrogen flow over the sample was used to evaporate the residual penetrant. All measurements were performed in an environmental controlled dust-free room with a temperature of $20{ }^{\circ} \mathrm{C}$ and humidity variations between 45 and $50 \%$.
To determine for the specific relaxation times, $\tau$, the dielectric loss peaks were fitted with the Havrilliak-Negami relation $^{30,31}$ (eq 3) using WinFit (Novocontrol Technologies).

$$
\varepsilon^{*}=\varepsilon_{\infty}+\frac{\Delta \varepsilon}{\left(1+(i \omega \tau)^{\alpha}\right)^{\beta}}
$$

Kramers-Kronig consistency checks were performed with the Lin-KK tool. ${ }^{32-35}$

In Situ FTIR Diffuse Reflectance Spectroscopy. DRIFT-FTIR spectra of $\sim 3 \mu \mathrm{m}$ thick matrimid films were obtained with a Tensor 27 FTIR spectrometer (Bruker optics) equipped with a high-temperature reaction chamber used in conjunction with the Praying Mantis accessory (Harrick). Absorption measurements were performed in the range of $400-4000 \mathrm{~cm}^{-1}$ with a resolution of $2 \mathrm{~cm}^{-1}$, and the sample scan time was $1 \mathrm{~min}$. A background measurement was performed prior to each measurement using a clean silicon wafer with a native oxide.

For the temperature-dependent measurements, an annealed $3 \mu \mathrm{m}$ thick matrimid sample was heated as with the annealing of the thin film samples. An additional temperature-dependent measurement was performed with a ramp of $1{ }^{\circ} \mathrm{C} \mathrm{min}{ }^{-1}$ from 25 to $350{ }^{\circ} \mathrm{C}$ with steps of $25^{\circ} \mathrm{C}$. At each temperature step, the sample was held for $30 \mathrm{~min}$. The sample was then cooled down again at a rate of $1{ }^{\circ} \mathrm{C} \mathrm{min}-1$, and a $30 \mathrm{~min}$ isothermal plateau was set at $325,300,250,150,125,75$, and $25^{\circ} \mathrm{C}$.

For the penetrant-induced swelling measurement, the cell was kept at constant temperature of $25{ }^{\circ} \mathrm{C}$. Prior to the exposure of the penetrant, a dry measurement of the matrimid was taken. Next, the sample cell was filled with the liquid penetrant, with care taken to not cover the sample. After this, by using two bubblers in series, saturated penetrant vapor was flowed through the cell at a rate of $200 \mathrm{~mL} \mathrm{~min}^{-1}$, and over a period of $24 \mathrm{~h}$, a spectrum was recorded every $10 \mathrm{~min}$. To account for the signal of the penetrant vapor during the penetrant-induced swelling measurement, a reference measurement on a bare silicon wafer was performed using the same settings.

\section{RESULTS AND DISCUSSION}

Thermal History Effects. Matrimid is a glassy polymer, consequently the thermal history of the polymer will influence the physical properties. Upon heating a polyimide above its glass transition temperature, both crystallization ${ }^{36-39}$ and cross-linking ${ }^{40-42}$ phenomena have been reported. When considering matrimid, a polyimide with steric hindrance to linearization, reports of cross-linking can be found in the literature. ${ }^{42-45}$ To determine whether cross-linking took place and to gain more information on the thermal properties of the sample after the thermal annealing, the annealing was followed in situ with temperature-dependent spectroscopic ellipsometry. In Figure 3, the thickness and optical properties of a freshly spin-coated $290 \mathrm{~nm}$ matrimid film as function of temperature and time are shown. On the basis of the optical modeling of the matrimid film, anisotropy was observed in the freshly spincoated film (see the Supporting Information for modeling details), which can be the result of stress induced during the spin-coating process. Upon heating, the decrease in thickness caused by the removal of the spin-coating solvent competes with the thermal expansion induced by the increase in temperature as is shown in Figure 3. Isothermal annealing of the matrimid above $350{ }^{\circ} \mathrm{C}$ removed the anisotropy within the 

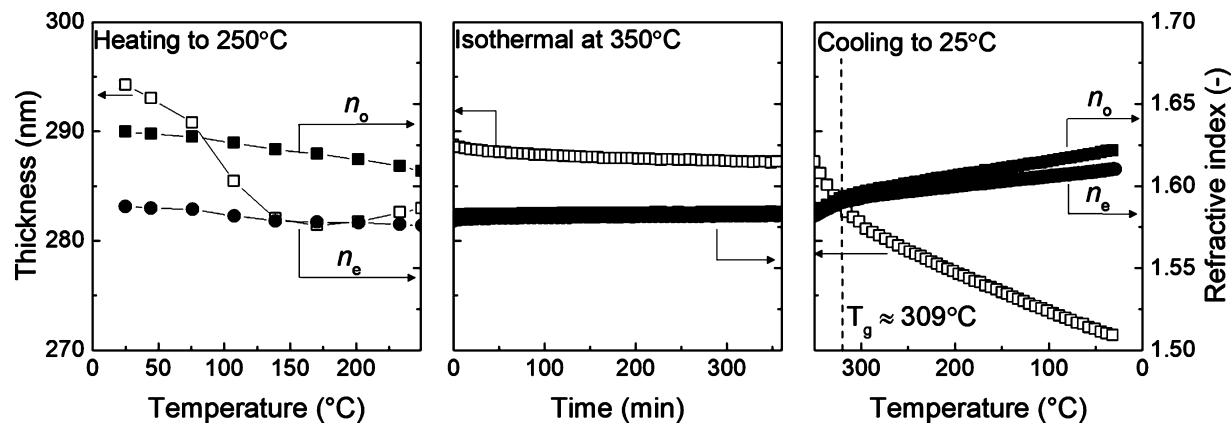

Figure 3. Thickness (left axis), ordinary refractive index $\left(n_{\mathrm{o}}\right.$ at $\left.632.8 \mathrm{~nm}\right)$, and extraordinary refractive index $\left(n_{\mathrm{e}}\right.$ at $\left.632.8 \mathrm{~nm}\right)$ (right axis) as function of the annealing temperature and time. Upon heating to $250^{\circ} \mathrm{C}$ (left), during $6 \mathrm{~h}$ isothermal stage at $350{ }^{\circ} \mathrm{C}$ (middle) and upon cooling to $25{ }^{\circ} \mathrm{C}$ (right). A glass transition temperature was observed at $309^{\circ} \mathrm{C}$.
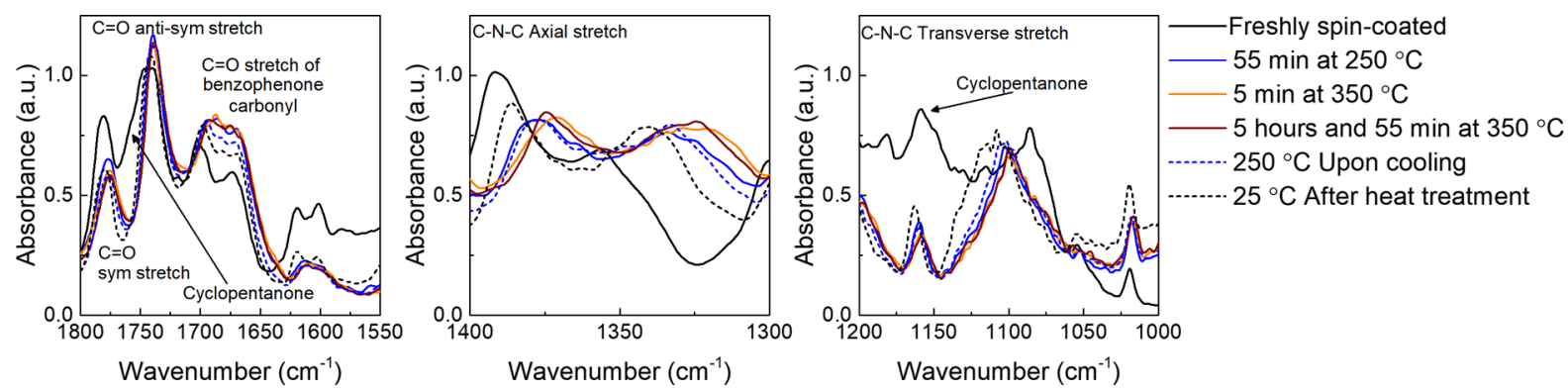

Figure 4. Temperature-dependent DRIFT-FTIR absorbance spectra of matrimid during the annealing of a freshly spin-coated film at $25-350{ }^{\circ} \mathrm{C}$. At $250^{\circ} \mathrm{C}$, all cyclopentanone is removed (left and right figure). For the $\mathrm{C}-\mathrm{N}-\mathrm{C}$ axial stretch (middle), a strong shift to the lower wavelengths was observed upon heating to $350{ }^{\circ} \mathrm{C}$, which was reversed on cooling.

sample, and a small decrease in thickness $(\sim 1 \mathrm{~nm})$ was observed. Upon cooling down to $25^{\circ} \mathrm{C}$, a glass transition temperature was observed at $309{ }^{\circ} \mathrm{C}$ and the anisotropy increased. The complete thickness and refractive index dependence as function of the annealing process is provided in the Supporting Information.

After the thermal heat treatment, the matrimid films were found to be insoluble in cyclopentanone. In Figure 4, the in situ temperature-dependent DRIFT-FTIR absorbance as measured at various stages of the annealing treatment is shown. Upon the evaporation of the spin-coating solvent, cyclopentanone, strong changes in the absorbance spectra for each specific vibration were observed. Cyclopentanone has a broad and strong absorbance peak at $1750 \mathrm{~cm}^{-1}$, and a strong absorbance peak at $1150 \mathrm{~cm}^{-1}$, which are both visible in the fresh spin-coated sample but disappear after the first heating ramp to $250{ }^{\circ} \mathrm{C}$, showing that the cyclopentanone was removed. Upon subsequent heating to $350{ }^{\circ} \mathrm{C}$, the strongest change was observed for the $\mathrm{C}-\mathrm{N}-\mathrm{C}$ axial stretch, which shifts to the lower wavenumbers. This can indicate that polymer chains are brought in closer proximity to each other and a more conjugated system was obtained. This is in agreement with literature, where it is suggested slight crosslinking occurs via the formation of charge-transfer complexes between the benzene rings and the imide rings, allowing the transfer of $\pi$-electrons. ${ }^{39,46-48}$

Penetrant-Induced Swelling. In Situ Spectroscopic Ellipsometry. The SD and normalized ordinary and extraordinary refractive indices as measured with iSE are shown in Figure 5. Matrimid swells about seven times more in toluene $(\mathrm{SD}=28 \%)$ versus $n$-hexane ( $\mathrm{SD}=4 \%)$, which is comparable to what has been observed before. ${ }^{49}$ The absolute observed SDs are lower compared with previous literature results
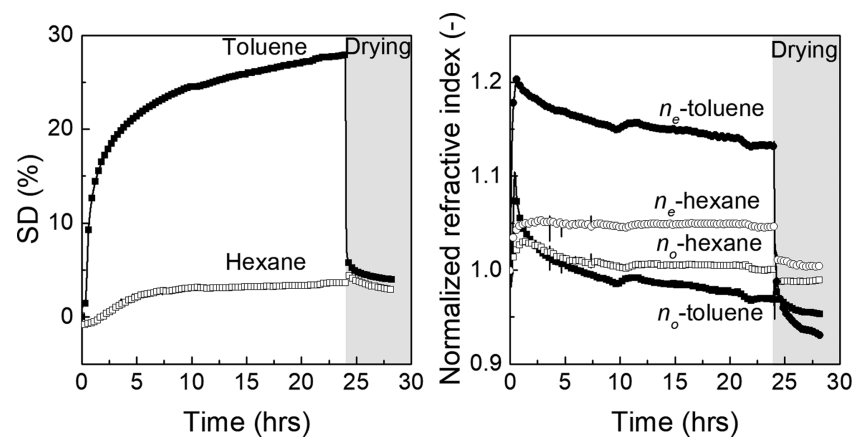

Figure 5. SD (left) and the normalized refractive indices at $632.8 \mathrm{~nm}$ (right) as function of time in a $\sim 260 \mathrm{~nm}$ matrimid film. The filled black symbols represent the swelling data in toluene, while the open symbols represent the swelling data in $n$-hexane. The gray area refers to the removal of the solvent from the matrimid film by applying a nitrogen flow over the sample. It can be observed that upon drying that $\mathrm{SD}>0$, meaning the penetrant is not removed completely.

because of the difference in annealing temperatures used ( 250 ${ }^{\circ} \mathrm{C}$ in the literature vs $350{ }^{\circ} \mathrm{C}$ in this study). Interestingly, the anisotropy within the matrimid film remained and even increased upon exposure to the penetrant. This observed strengthening of the degree of anisotropy within the matrimid film upon swelling is likely the result of the cross-linking of the matrimid film during the annealing treatment, allowing for a stronger swelling effect in the direction of the optical axis $\left(n_{\mathrm{e}}\right)$ compared with the swelling perpendicular to the optical axis $\left(n_{\mathrm{o}}\right)$. This indicates that the matrimid chain structure is different in the $z$-direction as compared to the $x-y$ direction of the substrate. After subsequent drying of the swollen samples with a nitrogen flow, the matrimid samples remained swollen 
up to $\sim 5-6 \%$, indicating that the last traces of the penetrant are harder to remove from the polymer.

Broadband Dielectric Spectroscopy. To understand the difference in SD of matrimid in $n$-hexane and in toluene, BDS was applied in situ to probe the interactions of the polymer chains with the two different penetrants. In the literature, for matrimid 5218, Comer et al. observed a $\gamma$-relaxation, $\beta$ relaxation, and $\alpha$-relaxation. Konnertz et al. observed a broad $\beta^{*}$-relaxation and an additional conductivity term. Further mechanical measurements showed that the observed broad $\beta^{*}$ relaxation consisted of two processes which merge together at higher frequencies or temperatures. Both Comer et al. and Konnertz et al. studied non-crosslinked matrimid, and thus, the behavior they observed is strongly dependent on the thermal history of the matrimid, which explains the differences in the relaxation behavior between these two studies.

In Figure 6A,B, the dielectric behavior of dry matrimid and of matrimid exposed to toluene at room temperature is shown.
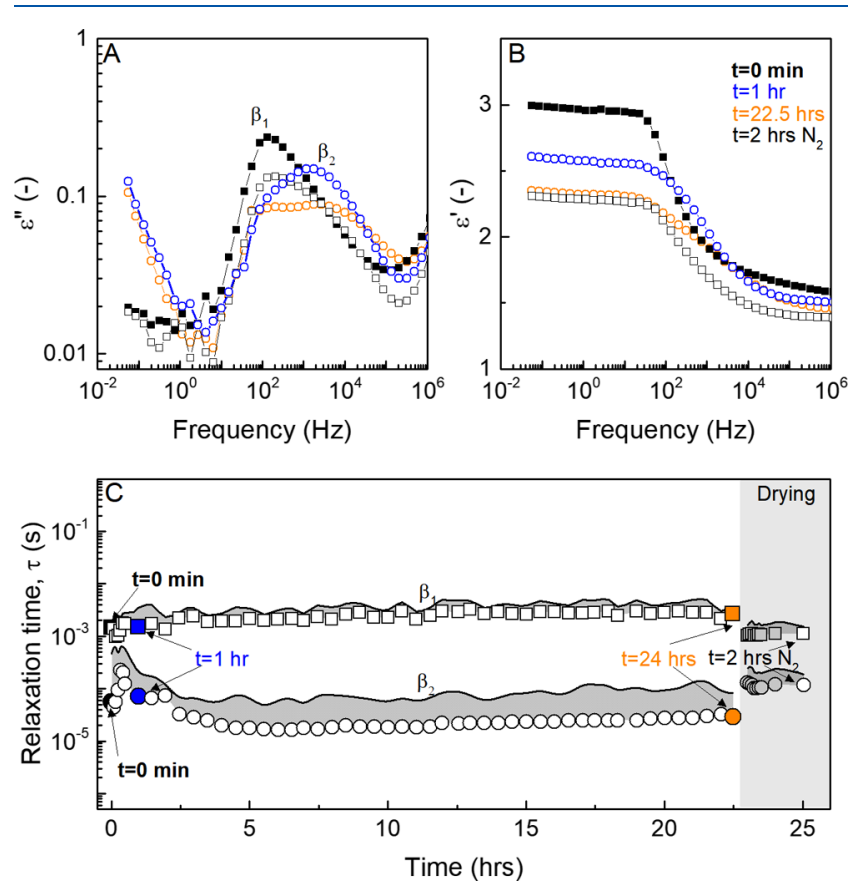

Figure 6. $\varepsilon^{\prime \prime}(\mathrm{A})$ and $\varepsilon^{\prime}$ (B) for a $\sim 260 \mathrm{~nm}$ dry matrimid film (closed black squares), exposed to toluene for $1 \mathrm{~h}$ (blue open circles), $22.5 \mathrm{~h}$ (orange open circles), and after $2 \mathrm{~h}$ of drying in a nitrogen flow after toluene exposure (open square). (C) Relaxation times of the two $\beta$ relaxations were determined for each frequency sweep time step and shown as a function of exposure time. The gray margin above the symbols represents the standard error of the fit (for visualization purposes in positive direction only).

For a dry matrimid sample after annealing, two overlapping $\beta$ relaxations were observed. Upon exposure to toluene, the two $\beta$-relaxations separated with $\beta_{2}$ shifting to higher frequencies. As shown during the ellipsometry measurements, at room temperature both toluene and $n$-hexane could not completely be removed upon drying with a dried nitrogen flow. For this reason, for toluene, upon drying with a continuous dried nitrogen flow, $\beta_{2}$ shifts back to a lower frequency, but not to the original frequency. In Figure $6 \mathrm{C}$, the relaxation times as obtained by the Havrilliak-Negami fits of the $\beta_{1^{-}}$and $\beta_{2^{-}}$ relaxation are shown as function of the exposure time to toluene. Within the first few hours of penetrant exposure, a continuous shift of the $\beta_{2}$-relaxation to the higher frequencies was observed, but after $\sim 5 \mathrm{~h}$, the dielectric behavior of matrimid in toluene was stable. The shift of the $\beta_{2}$-relaxation to the higher frequencies was shown to be consistent over two different experiments as shown in the Supporting Information. Furthermore, upon exposure to toluene, at the lower frequencies, an increase in the dielectric loss was observed. This increase may be a conductivity effect because of the presence of traces of contaminants in the toluene solution, which diffused into the matrimid because of the high SD of matrimid in toluene.

In Figure 7A,B, the dielectric behavior of dry matrimid and of matrimid exposed to $n$-hexane at room temperature is
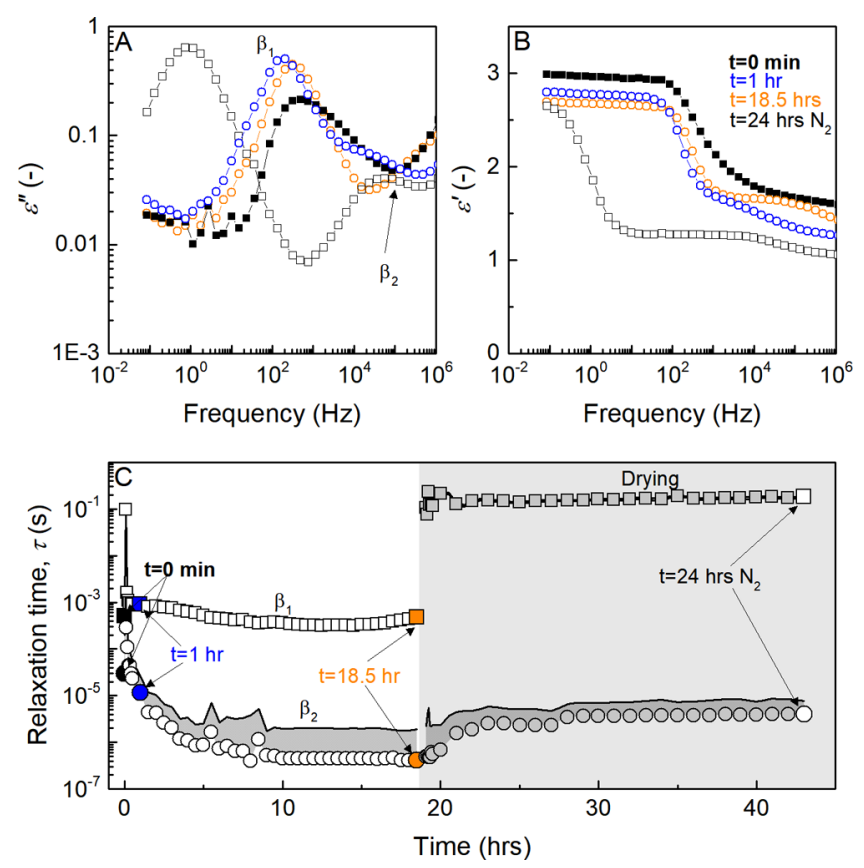

Figure 7. $\varepsilon^{\prime \prime}(\mathrm{A})$ and $\varepsilon^{\prime}$ (B) for a $\sim 260 \mathrm{~nm}$ dry matrimid film (closed black squares), exposed to $n$-hexane for $1 \mathrm{~h}$ (blue open circles), $22.5 \mathrm{~h}$ (orange open circles), and after $2 \mathrm{~h}$ of drying in a nitrogen flow after $n$-hexane exposure (open square). (C) Relaxation times of the two $\beta$ relaxations were determined for each frequency sweep time step and shown as function of exposure time. The gray margin above the symbols represents the standard error of the fit (for visualization purposes in positive direction only).

shown. The dielectric changes observed for matrimid exposed to $n$-hexane are not repeatable for each measured sample, unlike the case for toluene exposure. However, it is shown that in the case of $n$-hexane, both $\beta_{1}$ - and $\beta_{2}$-relaxations are influenced by the presence of $n$-hexane, and this behavior is not reversible as shown by the removal of $n$-hexane by a nitrogen flow. Also, in the case of $n$-hexane exposure, no additional increase in the dielectric loss at the low frequencies was observed. The difference for $n$-hexane compared with toluene is that the SD of matrimid in $n$-hexane is much lower compared with that in toluene, possibly inhibiting diffusion of contaminants into the matrimid.

The fact that toluene only affects the $\beta_{2}$-relaxation, namely, through speeding up the relaxation time, while in $n$-hexane both $\beta_{1}$ and $\beta_{2}$ are affected and both can be slowed down or can speed up, shows that both penetrant molecules have different interactions with matrimid. 
Diffuse Reflectance Fourier Transform Infrared Spectroscopy (DRIFT-FTIR). DRIFT-FTIR was used to gain a better understanding on the molecular origin of the $\beta$-relaxations as observed in matrimid. ${ }^{50,51}$ In Figure 8 , the $\mathrm{C}-\mathrm{N}-\mathrm{C}$ axial

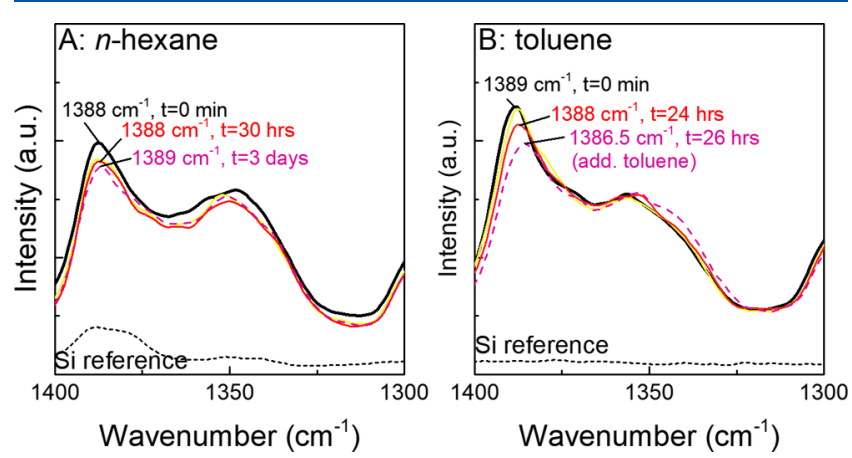

Figure 8. $\mathrm{C}-\mathrm{N}-\mathrm{C}$ axial stretch for a $\sim 3 \mu \mathrm{m}$ matrimid film on top of a silicon wafer in $n$-hexane (A) and in toluene (B). The dashed black line represents the background signal of the penetrant used as measured using a bare silicon wafer. The indicated time represents the exposure time to the penetrant. In case of toluene swelling, after $\sim 24$ $\mathrm{h}$, additional toluene was added to in the cell, to enhance the penetrant activity and to enhance the swelling and visualize the trend in swelling. In case of $n$-hexane, the hexane was already added in the beginning to ensure significant swelling for detection. The measurement was therefore continued for 3 days to detect a trend, but this was not found.

stretch absorbance of matrimid as function of the $n$-hexane vapor exposure time (A) and toluene vapor exposure time (B) is shown. For toluene exposure, with increasing toluene exposure times, a tendency to shift to lower wavenumbers with decreasing intensities (see Figure 8) was visible. In the case of $n$-hexane, no such trend was observed. For all other matrimid vibration modes, no significant change or trend was detected as a function of the penetrant exposure times. Although a similar change in the $\mathrm{C}-\mathrm{N}-\mathrm{C}$ axial shift was observed during the temperature-dependent measurement (see Figure 4), the changes observed during the penetrant-dependent measurement were less strong than as would have been expected based on the strong changes that were observed in the BDS spectra and the expected SDs for toluene and $n$-hexane, respectively. This is most likely due to the limited swelling that could be obtained during the penetrant-induced swelling measurement with DRIFT-FTIR. Unlike for the spectroscopic ellipsometry and BDS experiments, here, the swelling was induced using toluene and $n$-hexane vapor, generated by two bubblers in series. The design of the in situ cell was not optimal as such that it was highly likely a solvent activity lower than 1 (where 1 is the solvent activity as a pure liquid), was obtained. As shown by Favre et al., ${ }^{52}$ lower solvent activities result in significantly lower sorption of the penetrant. The lower sorption of the penetrant can result in smaller changes in the relaxation behavior of the polymer chains, decreasing the sensitivity of the DRIFT-FTIR measurement.

Interpretation Penetrant-induced Swelling in Matrimid. When exposed to toluene, a strong penetrant-induced swelling could be observed $(\sim 28 \%)$ with spectroscopic ellipsometry, and the relaxation time of $\beta_{2}$-relaxation was decreased as observed with BDS. This decrease in the relaxation time, indicates a decrease in energy, a trend which was observed for the $\mathrm{C}-\mathrm{N}-\mathrm{C}$ axial stretch in the DRIFTFTIR spectra. Together with the high SD, toluene presumably interacts in particular with the benzene group in the diamine (DAPI) breaking intersegmental interactions. This occurs as the $\pi-\pi$ interaction between the toluene molecule and the benzene ring in the matrimid polymer chain are stronger than the intersegmental interactions between the benzene rings (see also Figure 9). The role of the benzene ring and its accessibility

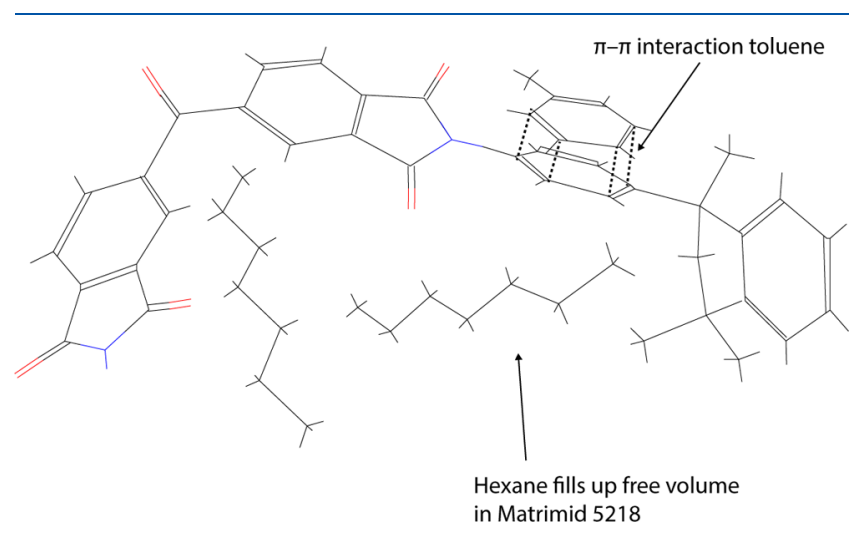

Figure 9. Schematic illustration of the different interactions between toluene and $n$-hexane with Matrimid 5218.

to the toluene molecule is also confirmed by the reported lower sorption rates in the literature for toluene in, for example, P84. ${ }^{49,53}$ P84 is a composite polyimide, where the diamine group is much less bulky, improving the alignment of the molecule. As a result, however, the benzene groups are much more difficult to access. A similar phenomenon based on polarity strength was suggested for the sorption of $\mathrm{CO}_{2}$ in cellulose acetate and polymethylmethacrylate. Koros ${ }^{54}$ showed that with an increasing easily accessible carboxyl concentration inside the polymer, the sorption of $\mathrm{CO}_{2}$ increased. It was therefore concluded that the interactions of $\mathrm{CO}_{2}$ with the polar groups carboxyl groups in the matrimid chain are stronger than the intermolecular interactions between the matrimid chain segments.

In the case of $n$-hexane sorption, the hexane is not able to interact with the matrimid polymer via either polar interactions or $\pi-\pi$ interactions and can only interact with the via Van der Waals interactions. Other than that, $n$-hexane will fill up the excess free volume available as indicated by the slight increase in the refractive index data in Figure 5, providing only for a limited interaction with the matrimid polymer chains. The fact that in the BDS spectra of matrimid in $n$-hexane nonconsistent changes were observed is possibly related to how locally the $n$ hexane molecule can penetrate in-between the matrimid polymer chain and interact with the methyl groups in the diamine (DAPI). However, because of the overlapping strong signal of $n$-hexane itself, this could not be confirmed via the DRIFT-FTIR measurements. Also, because van der Waals interactions are much weaker interactions compared with $\pi-\pi$ interactions, the current sensitivity of the DRIFT-FTIR measurement may be too low to measure noiseless signal changes as a result of $n$-hexane interactions with matrimid. To improve the sensitivity of the DRIFT-FTIR measurement, the signal intensity ought to be improved by ensuring that the in situ cell allows for liquid measurements.

To confirm the role of the $\pi-\pi$ interaction between the toluene and matrimid, swelling experiments with a bulky aromatic solvent such as mesitylene or xylene should be performed. Bulky aromatic solvents are more prone to steric 
hindrance, reducing the $\pi-\pi$ interactions and as a result a lower swelling should be observed.

\section{CONCLUSIONS}

In this work, the molecular origin of the different penetrant interactions with matrimid was investigated using a combination of in situ characterization techniques: SE, BDS, and DRIFT-FTIR.

The thermal annealing treatment applied to the matrimid films resulted in a small degree of cross-linking of the matrimid films, which caused the films to become insoluble in cyclopentanone. At room temperature, two overlapping $\beta$ relaxations were observed for dried matrimid films. Upon exposure to a penetrant, a separation of the two different $\beta$ relaxations was observed. In case of toluene exposure, a strong penetrant-induced swelling was observed $(\sim 28 \%)$, and the relaxation time of $\beta_{2}$-relaxation was decreased. Toluene is speculated to break up intersegmental interactions and to form a $\pi-\pi$ interaction with the benzene rings in the diamine, resulting in a decrease in energy of the $\mathrm{C}-\mathrm{N}-\mathrm{C}$ axial stretch as observed during the DRIFT-FTIR measurements. When matrimid was exposed to $n$-hexane, a $\mathrm{SD}$ of $\sim 4 \%$ was observed; however, BDS results show that $n$-hexane interacts with multiple molecular moieties in the matrimid chain, changing both $\beta$-relaxations. Unlike toluene, the $\beta$-relaxations were found to inconsistently change (speed up or slow down) versus toluene where the relaxation time consistently decreased. $n$-Hexane therefore likely only fills up the excess free volume available inside the polymer matrix and the induced relaxation time changes are likely governed by the local penetration of $n$-hexane in-between the matrimid polymer chains. The exact interaction of the $n$-hexane molecules with the different groups in matrimid could not be revealed because of the limited sensitivity that was obtained during the DRIFTFTIR measurement, which motivates further investigation into the improvement of in situ infrared spectroscopy cells designed for liquid measurements. To conclude, this work has revealed the nature of the molecular interactions between an aromatic and nonaromatic penetrant with matrimid. The obtained insights can be used to improve the understanding of solventinduced swelling of matrimid in OSN applications.

\section{ASSOCIATED CONTENT}

\section{S Supporting Information}

The Supporting Information is available free of charge on the ACS Publications website at DOI: 10.1021/acs.jpcb.9b00688.

Additional spectroscopic ellipsometry data, additional DRIFT-FTIR data, and reproducibility BDS measurements (PDF)

\section{AUTHOR INFORMATION}

\section{Corresponding Author}

*E-mail: n.e.benes@utwente.nl. Phone: +31534894288.

\section{ORCID}

Kristianne Tempelman: 0000-0003-2772-1820

Jeffery A. Wood: 0000-0002-9438-1048

Nieck E. Benes: 0000-0001-9716-069X

\section{Notes}

The authors declare no competing financial interest.

\section{ACKNOWLEDGMENTS}

The authors would like to thank Jan van Nieuwkasteele for his expertise with nanoelectrodes and help with the sample preparation for BDS, Bert Geerdink and Karin van den Nieuwenhuijzen for allowing us to measure with the DRIFTFTIR set-up and Emmanuel Mapesa for his BDS expertise and help with starting up the BDS experiments. This work is part of the research program TA-ISPT Fundamentals with project number 731.014.203, which is (partly) financed by the Netherlands Organization for Scientific Research (NWO).

\section{ADDITIONAL NOTE}

${ }^{a}$ Toluene has a low dipole moment of $0.375 \mathrm{D}$ and a very small electron donor parameter ${ }^{55}$ and is therefore considered as a non-polar molecule.

\section{REFERENCES}

(1) Liaw, D.-J.; Wang, K.-L.; Huang, Y.-C.; Lee, K.-R.; Lai, J.-Y.; Ha, C.-S. Advanced Polyimide Materials: Syntheses, Physical Properties and Applications. Prog. Polym. Sci. 2012, 37, 907-974.

(2) Qu, W.; Ko, T.-M.; Vora, R. H.; Chung, T.-S. Effect of Polyimides with Different Ratios of Para - to Meta - Analogous Fluorinated Diamines on Relaxation Process. Polymer 2001, 42, 6393-6401.

(3) Li, F.; Ge, J. J.; Honigfort, P. S.; Fang, S.; Chen, J.-C.; Harris, F. W.; Cheng, S. Z. D. Dianhydride Architectural Effects on the Relaxation Behaviors and Thermal and Optical Properties of OrganoSoluble Aromatic Polyimide Films. Polymer 1999, 40, 4987-5002.

(4) Dong, G.; Li, H.; Chen, V. Plasticization Mechanisms and Effects of Thermal Annealing of Matrimid Hollow Fiber Membranes for CO2 Removal. J. Membr. Sci. 2011, 369, 206-220.

(5) Bos, A.; Pünt, I. G. M.; Wessling, M.; Strathmann, H. Plasticization-Resistant Glassy Polyimide Membranes for CO2/CO4 Separations. Sep. Purif. Technol. 1998, 14, 27-39.

(6) Horn, N. R.; Paul, D. R. Carbon Dioxide Sorption and Plasticization of Thin Glassy Polymer Films Tracked by Optical Methods. Macromolecules 2012, 45, 2820-2834.

(7) Neyertz, S.; Brown, D. Molecular Dynamics Study of Carbon Dioxide Sorption and Plasticization at the Interface of a Glassy Polymer Membrane. Macromolecules 2013, 46, 2433-2449.

(8) Wessling, M.; Schoeman, S.; van der Boomgaard, T.; Smolders, C. A. Plasticization of Gas Separation Membranes. Gas Sep. Purif. 1991, 5, 222-228.

(9) Ismail, A. F.; Lorna, W. Penetrant-Induced Plasticization Phenomenon in Glassy Polymers for Gas Separation Membrane. Sep. Purif. Technol. 2002, 27, 173-194.

(10) Duthie, X.; Kentish, S.; Pas, S. J.; Hill, A. J.; Powell, C.; Nagai, K.; Stevens, G.; Qiao, G. Thermal Treatment of Dense Polyimide Membranes. J. Polym. Sci., Part B: Polym. Phys. 2008, 46, 1879-1890.

(11) Bos, A.; Pünt, I. G. M.; Wessling, M.; Strathmann, H. Suppression of CO2-Plasticization by Semiinterpenetrating Polymer Network Formation. J. Polym. Sci., Part B: Polym. Phys. 1998, 36, $1547-1556$.

(12) Kazarian, S. G.; Vincent, M. F.; Bright, F. V.; Liotta, C. L.; Eckert, C. A. Specific Intermolecular Interaction of Carbon Dioxide with Polymers. J. Am. Chem. Soc. 1996, 118, 1729-1736.

(13) Bos, A.; Pünt, I. G. M.; Wessling, M.; Strathmann, H. CO2Induced Plasticization Phenomena in Glassy Polymers. J. Membr. Sci. 1999, 155, 67-78.

(14) Vandezande, P.; Gevers, L. E. M.; Vankelecom, I. F. J. Solvent Resistant Nanofiltration: Separating on a Molecular Level. Chem. Soc. Rev. 2008, 37, 365-405.

(15) Gattiglia, E.; Russell, T. P. Swelling Behavior of an Aromatic Polyimide. J. Polym. Sci., Part B: Polym. Phys. 1989, 27, 2131-2144.

(16) Moon, Y. D.; Lee, Y. M. Dynamics of Solvent Diffusion in an Aromatic Polyimide. J. Appl. Polym. Sci. 1994, 51, 945-954. 
(17) Behnke, S.; Ulbricht, M. Thin-Film Composite Membranes for Organophilic Nanofiltration Based on Photo-Cross-Linkable Polyimide. React. Funct. Polym. 2015, 86, 233-242.

(18) Vanherck, K.; Vandezande, P.; Aldea, S. O.; Vankelecom, I. F. J. Cross-Linked Polyimide Membranes for Solvent Resistant Nanofiltration in Aprotic Solvents. J. Membr. Sci. 2008, 320, 468-476.

(19) Minelli, M.; Cocchi, G.; Ansaloni, L.; Baschetti, M. G.; De Angelis, M. G.; Doghieri, F. Vapor and Liquid Sorption in Matrimid Polyimide: Experimental Characterization and Modeling. Ind. Eng. Chem. Res. 2013, 52, 8936-8945.

(20) Neubauer, N.; Treß, M.; Winkler, R.; Mapesa, E. U.; Kipnusu, W. K.; Uhlmann, P.; Kremer, F. Molecular Dynamics of Swollen Poly(2-Vinylpyridine) Brushes. Macromolecules 2016, 49, 6101-6105.

(21) Arnold, F. E.; Bruno, K. R.; Shen, D.; Eashoo, M.; Lee, C. J.; Harris, F. W.; Cheng, S. Z. D. The origin of $\beta$ relaxations in segmented rigid-rod polyimide and copolyimide films. Polym. Eng. Sci. 1993, 33, 1373-1380.

(22) Bas, C.; Tamagna, C.; Pascal, T.; Dominique Alberola, N. On the Dynamic Mechanical Behavior of Polyimides Based on Aromatic and Alicyclic Dianhydrides. Polym. Eng. Sci. 2003, 43, 344-355.

(23) Vora, R. H.; Krishnan, P. S. G.; Goh, S. H.; Chung, T.-S. Synthesis and Properties of Designed Low-k Fluoro-Copolyetherimides. Part 1. Adv. Funct. Mater. 2001, 11, 361-373.

(24) Li, S.; Hsu, B.-L.; Li, F.; Li, C. Y.; Harris, F. W.; Cheng, S. Z. D. A study of polyimide thermoplastics used as tougheners in epoxy resins - structure, property and solubility relationships. Thermochim. Acta 1999, 340-341, 221-229.

(25) Li, F.; Fang, S.; Ge, J. J.; Honigfort, P. S.; Chen, J.-C.; Harris, F. W.; Cheng, S. Z. D. Diamine Architecture Effects on Glass Transitions, Relaxation Processes and Other Material Properties in Organo-Soluble Aromatic Polyimide Films. Polymer 1999, 40, 45714583

(26) Correia, N. T.; Moura Ramos, J. J. On the cooperativity of the $\beta$-relaxation: A discussion based on dielectric relaxation and thermally stimulated depolarisation currents data. Phys. Chem. Chem. Phys. 2000, 2, 5712-5715.

(27) Comer, A. C.; Kalika, D. S.; Rowe, B. W.; Freeman, B. D.; Paul, D. R. Dynamic Relaxation Characteristics of Matrimid Polyimide. Polymer 2009, 50, 891-897.

(28) Konnertz, N.; Böhning, M.; Schönhals, A. Dielectric Investigations of Nanocomposites Based on Matrimid and Polyhedral Oligomeric Phenethyl-Silsesquioxanes (POSS). Polymer 2016, 90, 89-101.

(29) Kappert, E. J.; Raaijmakers, M. J. T.; Ogieglo, W.; Nijmeijer, A.; Huiskes, C.; Benes, N. E. Temperature Calibration Procedure for Thin Film Substrates for Thermo-Ellipsometric Analysis Using Melting Point Standards. Thermochim. Acta 2015, 601, 29-32.

(30) Havriliak, S.; Negami, S. A Complex Plane Analysis of Adispersions in Some Polymer Systems. J. Polym. Sci., Part C: Polym. Symp. 1966, 14, 99-117.

(31) Havriliak, S.; Negami, S. A Complex Plane Representation of Dielectric and Mechanical Relaxation Processes in Some Polymers. Polymer 1967, 8, 161-210.

(32) Boukamp, B. A. A Linear Kronig-Kramers Transform Test for Immittance Data Validation. J. Electrochem. Soc. 1995, 142, 18851894.

(33) Schönleber, M.; Ivers-Tiffeee, E. Approximability of Impedance Spectra by RC Elements and Implications for Impedance Analysis. Electrochem. Commun. 2015, 58, 15-19.

(34) Schönleber, M.; Klotz, D.; Ivers-Tiffée, E. A Method for Improving the Robustness of Linear Kramers-Kronig Validity Tests. Electrochim. Acta 2014, 131, 20-27.

(35) Karlsruhe Institute of Technology. Kramers-Kronig Validity Test Lin-KK for Impedance Spectra. https://www.iam.kit.edu/wet/ english/Lin-KK.php (accessed Nov 20, 2018).

(36) Ishida, H.; Huang, M. T. Molecular Level Study of the Crystallization of a Thermoplastic Polyimide by Infrared Spectroscopy. J. Polym. Sci., Part B: Polym. Phys. 1994, 32, 2271-2282.
(37) Heberer, D. P.; Cheng, S. Z. D.; Barley, J. S.; Lien, S. H. S.; Bryant, R. G.; Harris, F. W. Crystallization and Morphology of Semicrystalline Polyimides. Macromolecules 1991, 24, 1890-1898.

(38) Hsiao, B. S.; Sauer, B. B.; Biswas, A. Crystallization Study of a Thermoplastic Polyimide (New-TPI). J. Polym. Sci., Part B: Polym. Phys. 1994, 32, 737-747.

(39) Wilson, D.; Stenzenberger, H. D.; Hergenrother, P. M. Polyimides; Springer, 1990.

(40) Yanagishita, H.; Maejima, C.; Kitamoto, D.; Nakane, T. Preparation of Asymmetric Polyimide Membrane for Water/Ethanol Separation in Pervaporation by the Phase Inversion Process. J. Membr. Sci. 1994, 86, 231-240.

(41) Kuroda, S.-i.; Terauchi, K.; Nogami, K.; Mita, I. Degradation of aromatic polymers-I. Rates of crosslinking and chain scission during thermal degradation of several soluble aromatic polymers. Eur. Polym. J. 1989, 25, 1-7.

(42) Kuroda, S.-i.; Mita, I. Degradation of aromatic polymers-II. The crosslinking during thermal and thermo-oxidative degradation of a polyimide. Eur. Polym. J. 1989, 25, 611-620.

(43) Bos, A.; Pünt, I. G. M.; Wessling, M.; Strathmann, H. Plasticization-Resistant Glassy Polyimide Membranes for $\mathrm{CO} 2 / \mathrm{CO} 4$ Separations. Sep. Purif. Technol. 1998, 14, 27-39.

(44) Bateman, J.; Gordon, D. Soluble Polyimides Derived from Phenylindane Diamines and Dianhydrides. U.S. Patent 3,856,752A, December 1974.

(45) Falcigno, P.; Masola, M.; Williams, D.; Jasne, S. Comparison of Properties of Polyimides Containing DAPI Isomers and Various Dianhydrides. Polyimides: Materials, Chemistry and Characterization, Proceedings of the Third International Conference on Polyimides; Elsevier: Ellenville, 1988.

(46) Dine-Hart, R. A.; Wright, W. W. A Study of Some Properties of Aromatic Imides. Makromol. Chem. 1971, 143, 189-206.

(47) Kawakami, H.; Anzai, J.; Nagaoka, S. Gas Transport Properties of Soluble Aromatic Polyimides with Sulfone Diamine Moieties. J. Appl. Polym. Sci. 1995, 57, 789-795.

(48) Dinan, F. J.; Schwartz, W. T.; Wolfe, R. A.; Hojnicki, D. S.; Clair, T. S.; Pratt, J. R. Solid-State 13C-NMR Spectral Evidence for Charge Transfer Complex Formation in Aromatic Diimides and Dianhydrides. J. Polym. Sci., Part A: Polym. Chem. 1992, 30, 111-118.

(49) Kappert, E. J.; Raaijmakers, M. J. T.; Tempelman, K.; Cuperus, F. P.; Ogieglo, W.; Benes, N. E. Swelling of 9 Polymers Commonly Employed for Solvent-Resistant Nanofiltration Membranes: A Comprehensive Dataset. J. Membr. Sci. 2019, 569, 177-199.

(50) Jasiurkowska-Delaporte, M.; Kossack, W.; Kipnusu, W. K.; Sangoro, J. R.; Iacob, C.; Kremer, F. Glassy Dynamics of Two Poly(Ethylene Glycol) Derivatives in the Bulk and in Nanometric Confinement as Reflected in Its Inter- and Intra-Molecular Interactions. J. Chem. Phys. 2018, 149, 064501.

(51) Mijović, J.; Zhang, H. Local Dynamics and Molecular Origin of Polymer Network-Water Interactions as Studied by Broadband Dielectric Relaxation Spectroscopy, FTIR, and Molecular Simulations. Macromolecules 2003, 36, 1279-1288.

(52) Favre, E.; Schaetzel, P.; Nguygen, Q. T.; Clément, R.; Néel, J. Sorption, Diffusion and Vapor Permeation of Various Penetrants through Dense Poly(Dimethylsiloxane) Membranes: A Transport Analysis. J. Membr. Sci. 1994, 92, 169-184.

(53) Beerlage, M. A. M. Polyimide Ultrafiltration Membranes for Non-Aqueous Systems. Ph.D. Dissertation, University of Twente, 1994.

(54) Koros, W. J. Simplified Analysis of Gas/Polymer Selective Solubility Behavior. J. Polym. Sci., Polym. Phys. Ed. 1985, 23, 16111628.

(55) Marcus, Y. The Effectivity of Solvents as Electron Pair Donors. J. Solution Chem. 1984, 13, 599-624. 